\title{
Assessment of the acid resistance behaviour of dentin tubules occluded by different desensitizers
}

\author{
Fatih Karayürek ${ }^{1} \oplus$, Osman Fatih Arpağ2 \\ ${ }^{1}$ Çankırı Karatekin University, Faculty of Dentistry, Department of Periodontology, Çankırı, Turkey \\ 2 Mustafa Kemal University, Faculty of Dentistry, Department of Periodontology, Hatay, Turkey
}

\section{Correspondence:}

\section{Dr. Fatih KARAYÜREK}

Çankırı Karatekin University, Faculty of

Dentistry, Department of

Periodontology, Çankırı, Turkey

E-mail:fatihkarayurek@

karatekin.edu.tr

Received: 3 April 2020

Accepted: 2 September 2020

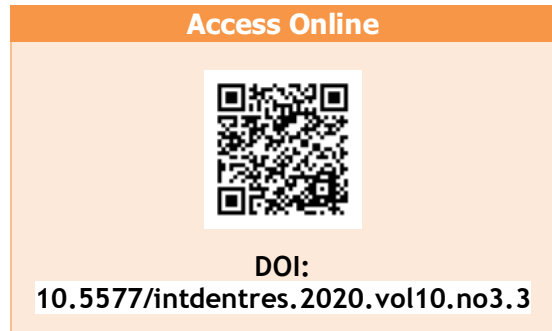

\section{Introduction}

The dentin layer is exposed due to the gingival recession caused by an insufficient amount of bone (1), periodontal diseases (2), smoking (3), orthodontic appliances (4), oral piercing (5) and improper toothbrushing (5). As a result of the exposure of the dental tubules to mouth environment, dentinal (0.506).

\section{Abstract}

Aim: To evaluate the efficacy of in-office and home-based products in the prevention of dentinal hypersensitivity on dentin discs.

Methodology: Ninety-six dentin disc samples of $1 \mathrm{~mm}$ were divided equally into six groups as follows: TeethmateTM, Smartprotect ${ }^{\circledR}$, novamin ${ }^{\circledR}$, Arginine calcium carbonate, potassium oxalate with rinse and saline (control). After acid etching, test agents were applied, and eight samples in each group were subjected to citric acid. SEM examination (3000x) and statistical analysis were carried out.

Results: Before citric acid challenge, novamin $₫$ and teethmate had superiority when compared to others $(p<0.001)$, but there was no a statistical difference between novamin $₫$ and teethmate. After citric acid challenge, teethmate and smartprotect showed resistance on occluded tubules. The decreasing in the level of occluded tubules in novamin $\circledast$ group was statistically significant $(\mathrm{p}<0.05)$. In-office products including teethmate and smartprotect were found more successful compared to home-based products. Smartprotect resisted against to citric acid

Conclusion: Novamin ${ }^{\circledR}$ showed a successful occlusion in all tubules before acid challenge whereas; it was the most unsuccessful group after acid challenge when compared to other agents. In-office agents were found to be more successful in reducing dentine permeability than homecare products. In-office agents showed more resistance to acid attacks. Further studies are needed to assess the efficacy of desensitizer agents.

Keywords: Dentinal hypersensitivity, in vitro, tubule occlusion, SEM analysis, acid challenge.

How to cite this article: Karayürek F, Arpağ OF. Assessment of the acid resistance behaviour of dentin tubules occluded by different desensitizers. Int Dent Res 2020;10(3):80-9. https://doi.org/10.5577/intdentres.2020.vol10.no3.3 hypersensitivity $(\mathrm{DH})$, a short-term and sharp pain which could be triggered by hot, cold and chemical stimuli, may occur (6). Such kind of pain leads to poor quality of life in patients who are influenced in terms of their basic needs such as eating, drinking and maintaining oral hygiene $(7,8)$.

It is known that the hydrodynamic theory is in charge of DH (9). According to this assumption, it is claimed that the fluid movement with the effect of the 
above-mentioned stimulants in dentin tubules can increase the pressure over the pulp, thus causing the $\mathrm{DH}(10)$. So as to reduce the pain associated with $\mathrm{DH}$, the primary approach is to inhibit the fluid movements by mechanically occluding the tubules (11). In another way, the chemical agents such as potassium nitrate are claimed to block or suppress nerve conduction in dentin tubules (12). Protein precipitation, the laser application, and dentin adhesive agents may be listed as the other methods in the management of $\mathrm{DH}$ (13).

The approaches to eliminate $\mathrm{DH}$ are divided into two main categories as in-office and home-based approaches. Neither home-based products such as toothpaste and mouth rinse nor in-office agents are not presented as ideal agents. The main task of these agents is to create a barrier in the dentin tubules to prevent temperature transitions and thereby reduce the sensitivity of the dentin. These home-based products include agents with active ingredients such as novamin $₫, 8 \%$ arginine-calcium carbonate (ACC) and potassium oxalate (PO). Novamin $®$, a commercial name known as calcium sodium phosphosilicate, is effective to occlude dentin permeability (14). Arginine and calcium both in ACC and in saliva constitute a coating in dentin tubules by collaborating calcium and phosphate within the dentin layer (15). Recent studies show that PO can be topically used to occlude dentin tubules (16). These agents can be directly utilized in social life by individuals suffering from dentinal hypersensitivity. Furthermore, the clinicians benefit from professionally applicable certain agents in order to relieve pain in patients with $\mathrm{DH}$. One of these agents containing tetra-calcium phosphate and dicalcium phosphate anhydride is Teethmate ${ }^{\circledR}$ (TM). Another one frequently utilized in dental practice is SmartProtect $®$ (SP), which contains glutaraldehyde, triclosan, olaflur, and 2-propanol providing closure in dentin tubules through its flour content (17).

The objectives of current experimental study were to detect the efficacy of in-office and home-based products in order to constitute the dentin occlusion and to determine the resistance of test products to acid attacks. The null hypothesis of the present study was that there was no difference among the effect of the agents on the dentine discs in terms of occlusion in the dentine tubules and there was no difference in terms of the resistance of the dentinal occlusion created by the agents to the acid challenge.

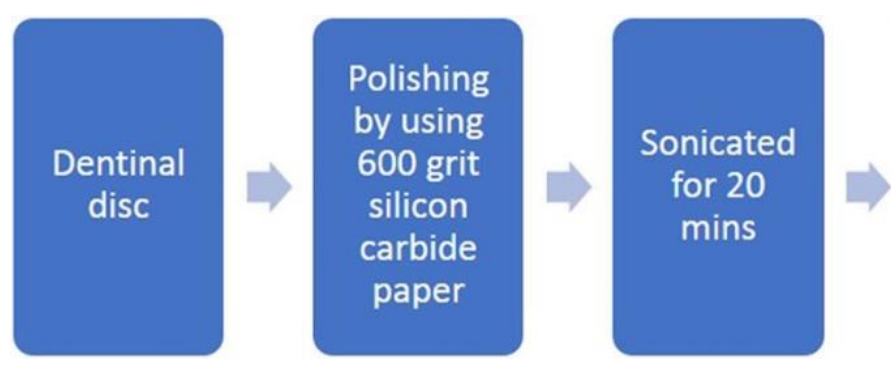

\section{Materials and Methods}

\section{Study design and sample preparation}

The ethical approval required for the current study was obtained from the Karabük University non-invasive clinical research ethical committee (4/23, $03 / 28 / 2018)$. This study was carried out on third molar teeth extracted from patients (impacted teeth that are not affected by the external conditions as much as possible) without any restoration and caries. The extracted third molars were conserved in saline until they were examined at the laboratory. Ninety-six dentin disc samples (each disc $1.09 \mathrm{~mm} \pm 0.16$-thick) were obtained from all teeth using the Secotom 50 (Struers, Denmark) cutting device. The occlusal enamel was eliminated from the dentin discs and the surface of disc was kept apart from pulp horns. These samples were divided into six groups with sixteen discs in each group. The first and the second groups were treated with an in-office application such as Teethmate $®$ (group TM) and SmartProtect ${ }^{\circledR}$ (group SP), respectively. The third, fourth and fifth groups were treated with Novamin ${ }^{\circledR}$ (group N), ACC (group ACC), $1.4 \%$ PO (group PO) respectively. Lastly, the sixth group was evaluated as control (Group C) and samples in this group were only kept in saline without being treated. All samples were polished using 600 grit silicon carbide paper (Metkon, Turkey) so as to remove intended sections on the disc surface. After obtaining a uniform surface, the dentine discs were preserved in distilled water and sonicated for $\mathbf{2 0}$ minutes to eliminate foreign substances. Afterward, the samples were rinsed with saline. In order to open the dentinal tubules, the dentine discs were etched in a Petri dish with $37.5 \%$ phosphoric acid (i-dental; Medicinos Linjia UAB, Lithuania) for 30 seconds (Figure 1, 2). After opening the dentinal tubules, the discs were rinsed with distilled water again and sonicated using an ultrasonic cleaner (Alex Machine, Turkey) for ten minutes in order to remove phosphoric acid residue. Before the scanning electron microscope (SEM) analysis, the samples were safely conserved in phosphate-buffered saline (PBS, ph=7) until micrographs are obtained (Fig 3), (Table 1).

Figure 1. The dentin discs preparation and examination process before SEM analysis 


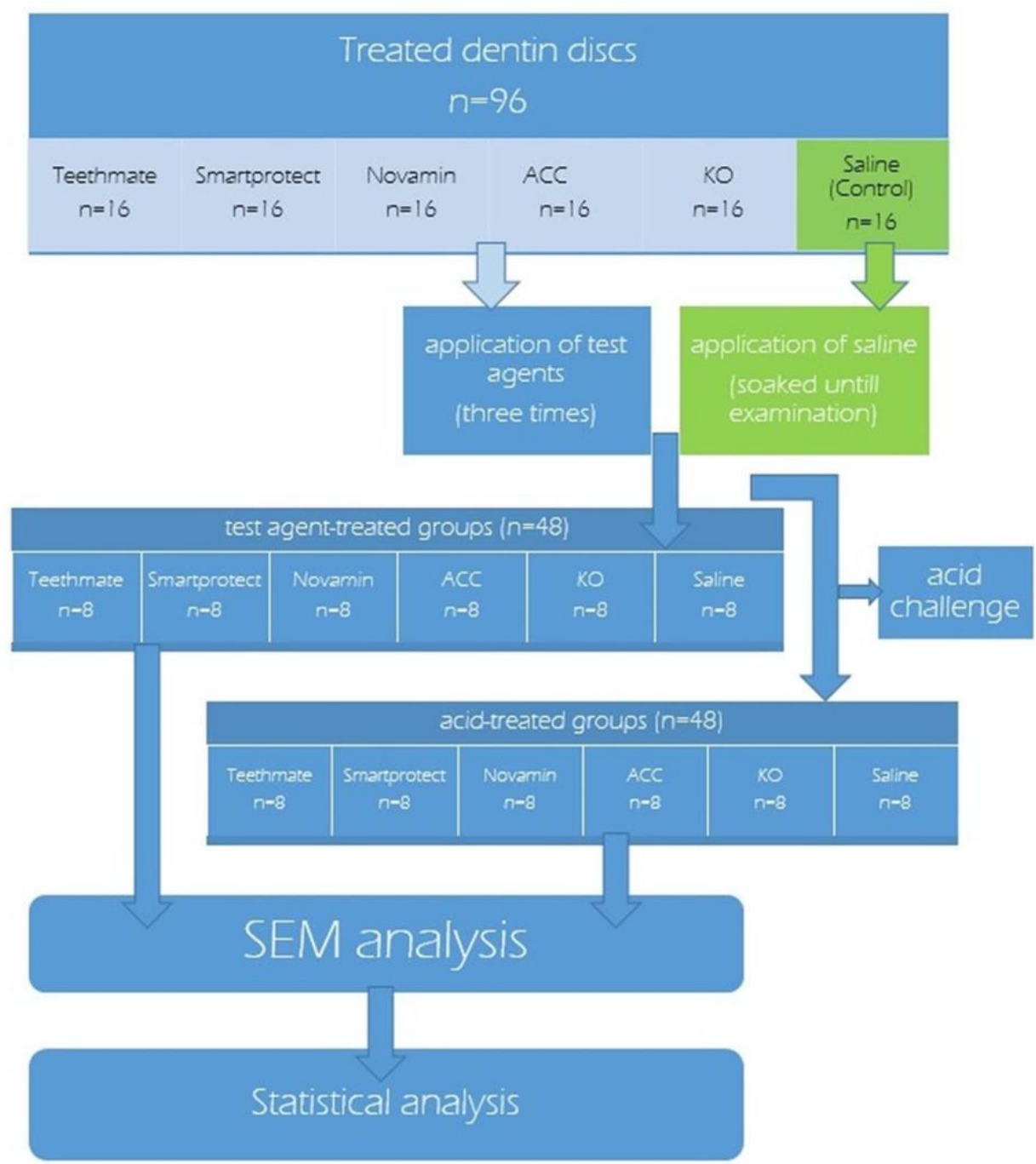

Figure 2. The flow chart of study

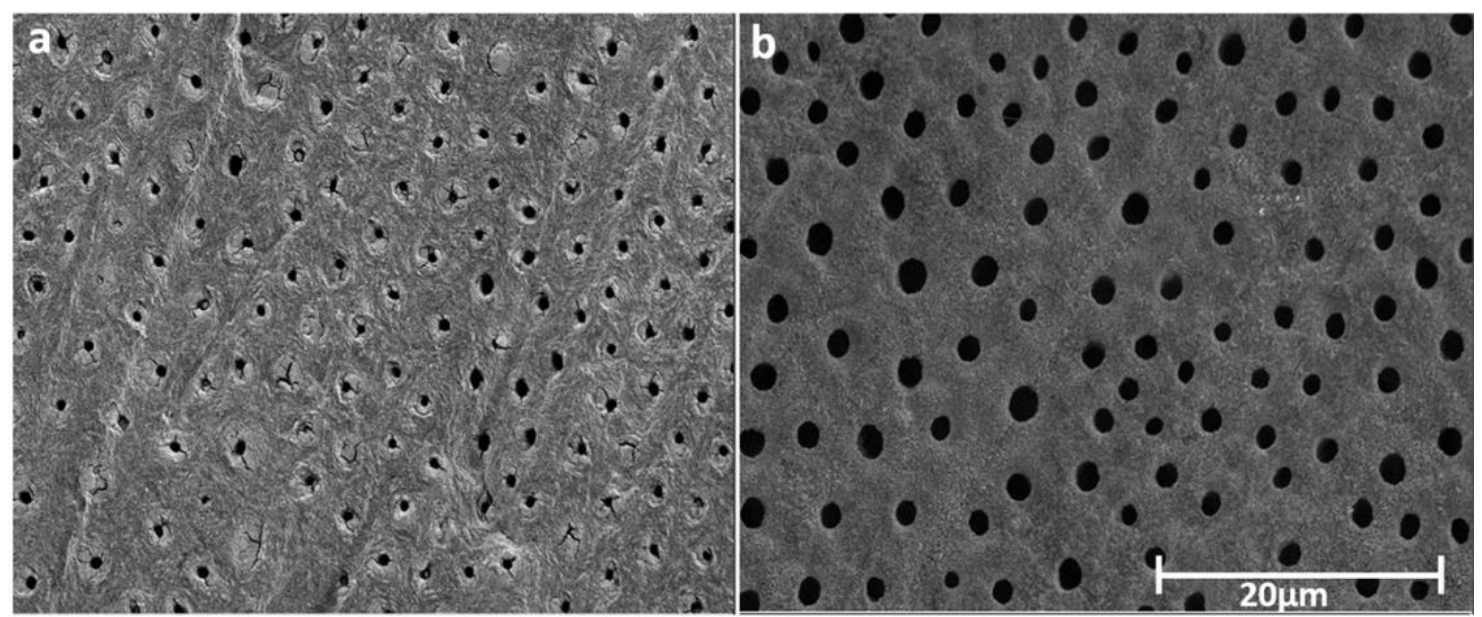

Figure 3. Opening of occluded dentine tubules before applying test agents of dentin discs. a: $37.5 \%$ before orthophosphoric acid, b: $37.5 \%$ after orthophosphoric acid. 
Table 1. Ingredients, manufacturers and usage of the desensitizers used in the study.

\begin{tabular}{|c|c|c|c|}
\hline Test Agents & Active Ingredients & Producing Company & Usage \\
\hline $\begin{array}{l}\text { Teethmate } \\
\text { (In office) }\end{array}$ & $\begin{array}{l}\text { Tetracalcium phosphate, } \\
\text { Dicalcium phosphate } \\
\text { anhydrous }\end{array}$ & $\begin{array}{l}\text { Teethmate Desensitizer, } \\
\text { Kuraray Noritake } \\
\text { Dental Inc., Nigata, Japan }\end{array}$ & $\begin{array}{c}\text { Powder and liquid are mixed and for } \\
\text { more than } 15 \text { seconds and mixture is } \\
\text { applied }\end{array}$ \\
\hline $\begin{array}{l}\text { Smartprotect } \\
\text { (In office) }\end{array}$ & $\begin{array}{l}\text { Glutaraldehyde, triclosan, } \\
\text { olaflur, 2-propanol in an } \\
\text { aqueous solution }\end{array}$ & $\begin{array}{l}\text { Smartprotect } \circledast \text {, The } \\
\text { Dental Advisor, Detax, } \\
\text { Ettlingen, Germany }\end{array}$ & $\begin{array}{l}\text { Dry dentin disc surface is applied with } \\
\text { a smart brush for } 20 \text { seconds. }\end{array}$ \\
\hline $\begin{array}{l}\text { Novamin } \\
\text { (Home-based) }\end{array}$ & $\begin{array}{c}\text { Calcium sodium } \\
\text { phosphosilicate (NOVAMIN) }\end{array}$ & $\begin{array}{l}\text { Sensodyne }{ }^{\circledR}, \text { SmithKline } \\
\text { Beecham Inc., Berks, } \\
\text { England }\end{array}$ & $\begin{array}{l}\text { Gently applied to dentine surfaces } \\
\text { with a soft toothbrush }\end{array}$ \\
\hline $\begin{array}{c}\text { ACC } \\
\text { (Home-based) }\end{array}$ & $\begin{array}{l}\text { Arginine }(8 \%) \text {, Calcium } \\
\text { carbonate, }\end{array}$ & $\begin{array}{c}\text { Colgate }{ }^{\circledR} \text { Sensitive Pro- } \\
\text { ReliefTM, Colgate Oral } \\
\text { Pharmaceuticals Inc., New } \\
\text { York, NY, USA }\end{array}$ & $\begin{array}{l}\text { Gently applied to dentine surfaces } \\
\text { with a soft toothbrush }\end{array}$ \\
\hline $\begin{array}{l}\text { Potassium } \\
\text { oxalate } \\
\text { (Home-based) }\end{array}$ & 1.4\% Dipotassium oxalate & $\begin{array}{l}\text { Listerine } ® \text {, Johnson \& } \\
\text { Johnson, Sezanne, France }\end{array}$ & $\begin{array}{l}\text { The dentin discs are shaken in } 10 \mathrm{ml} \text { of } \\
\text { liquid for } 60 \text { seconds. }\end{array}$ \\
\hline
\end{tabular}

\section{Application of test agents}

In the experimental procedure, all the samples were treated with PBS, and both TM and SP were applied onto smooth dentine surface according to the manufacturer's recommendation. Novamin ${ }^{\circledR}$ and ACC were kindly applied onto the surface of the dentin discs. The samples in group PO were subjected to the PO-containing rinse in a Petri dish according to manufacturer's instructions. After the applications, the samples were kept at room temperature for five minutes. After this, the samples were transferred to PBS for five minutes. Finally; the samples were rinsed with distilled water. This process was repeated three times (18). Half of the sixteen samples in each group were randomly selected in order to be evaluated for SEM analysis. The selected samples were prepared for SEM analysis through being coated with a layer of gold with a sputter coater (Quorum, United Kingdom).

\section{Acid challenge}

The remaining samples from each group were placed in $6 \%$ citric acid $(\mathrm{pH}=2.1)$ in a Petri dish for one minute and then rinsed in saline for two minutes. Finally, the acid-exposed samples were coated with a layer of gold for SEM analysis (Fig. 4).

\section{SEM analysis}

SEM analysis was carried out using the Zeiss Ultraplus SEM machine (Zeiss, Germany). SEM images were taken at 3000x magnification. $10 \mathrm{kV}$ electron beam voltage was used for coated samples and $2 \mathrm{kV}$ electron beam voltage for uncoated samples. Charge compensation equipment was also used for uncoated samples. During the SEM analysis, the micrographs were taken from the dentin discs for certain circumstances. Firstly, they were taken following acid etching to confirm whether the dentinal tubules were fully opened. After the micrographs were taken from the uncoated samples, test agents were applied. Secondly, SEM analysis was carried out to examine the effectiveness of the test groups. Thirdly, micrographs were taken from the dentin discs to evaluate the effect of the citric acid challenge on occlusion in dentinal tubules. For each one of the examined dentin discs, six non-adjacent images were taken. The assessment was carried out by scoring. According to this scoring: score 1 was given for the case of $100 \%$ occluded tubules, score 2 for mostly occluded ( $50-<100 \%$ occluded), score 3 for partial occluded (25- $<50 \%$ occluded), score 4 for little occluded ( $<25 \%$ occluded), and lastly score 5 for non-occluded ( $0 \%$ occluded).

\section{Statistical Analysis}

Data were analysed through IBM SPSS V23. Compliance with normal distribution was examined with Shapiro Wilk test. The intra-class correlation coefficient (ICC) was used for the similarity evaluation between the reviewers. Since the similarity between the reviewers was high, comparisons were made by averaging according to groups. Kruskal-Wallis test was used in the comparison of the data with abnormal distribution per groups. Wilcoxon test was used in the comparison of intragroup results before and after citric acid challenge. 


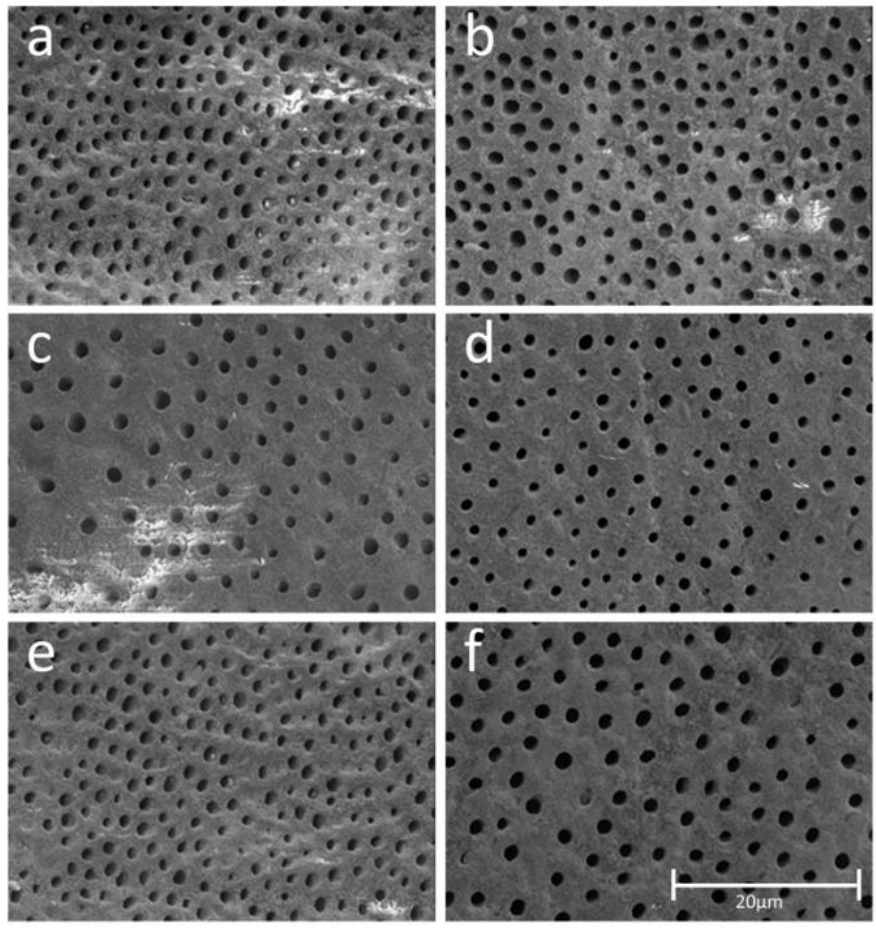

Figure 4. The etching with $37.5 \%$ orthophosphoric acid of samples by groups before the application of test agents. a: TM, b: SP, c: Novamin, d: ACC, e: PO, f: Control

\section{Results}

Before achieving the statistical results of the scores obtained in this study; the consistency between the scores recorded by the examiners was evaluated. It was observed that there was a strong positive relationship between the examiners. The consistency was found as respectively 0.952 and 0.910 before and after citric acid challenge (Table 2). In the statistical analysis, median values for all the test agents were obtained, and it was investigated whether there was a statistical significance on a median value. Between professionally applied test agents, group TM was found to be more effective than group SP in terms of the tubule occlusion $(p=0.000)$. However, it was observed that group SP occlusion was more resistant to citric acid attack than that of group TM and the difference between these agents was statistically significant $(p<0.001)$. In the comparison of the groups regarding the resistance against acid attack; the change in group TM was statistically significant while there was no change in the resistance of group SP $(p<0.001$, $\mathrm{p}=0.506$ ). (Table 3 and 5).

Table 2. Concordance between examiners

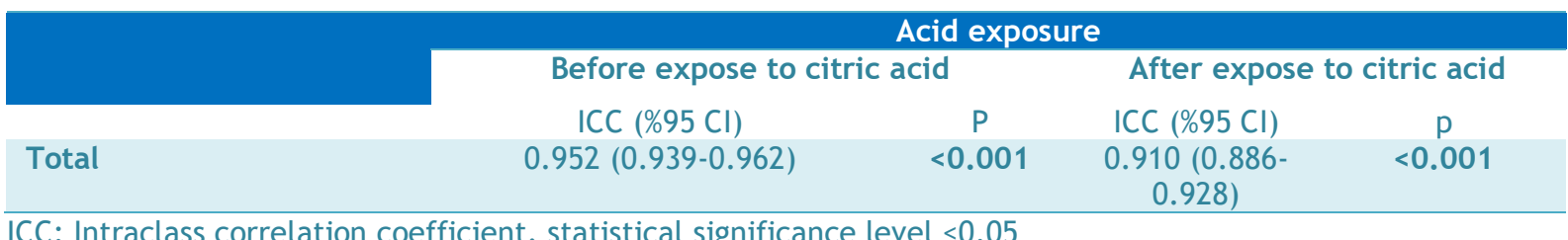

Table 3. Comparison of inter- and intra-groups median values after application of agent and acid

\begin{tabular}{lccc} 
Study groups & after agent & after acid & $p$ \\
Teethmate & $1.3(1-3)^{\mathrm{a}}$ & $2,5(1-4,5) \mathrm{a}$ & ${ }^{*} 0,001$ \\
Smartprotect & $3(1-5)^{\mathrm{bc}}$ & $3(2-5)^{\mathrm{ab}}$ & 0,506 \\
Novamin & $1(1-2,5)^{\mathrm{a}}$ & $4(2-5)^{\mathrm{bc}}$ & ${ }^{*} 0,001$ \\
Arginine calcium carbonate & $2,5(1-5)^{\mathrm{b}}$ & $3,5(2-5)^{\mathrm{ab}}$ & ${ }^{*} 0,001$ \\
Potassium oxalate & $3,5(2,5-5)^{\mathrm{c}}$ & $3,5(2-5)^{\mathrm{ab}}$ & ${ }^{*} 0,001$ \\
Control & $5(5-5)^{\mathrm{d}}$ & $5(5-5)^{\mathrm{d}}$ & 1,000 \\
\hline
\end{tabular}

Different letters show the difference between groups, values in parenthesis present lower and upper limits, significance level; <0,05 

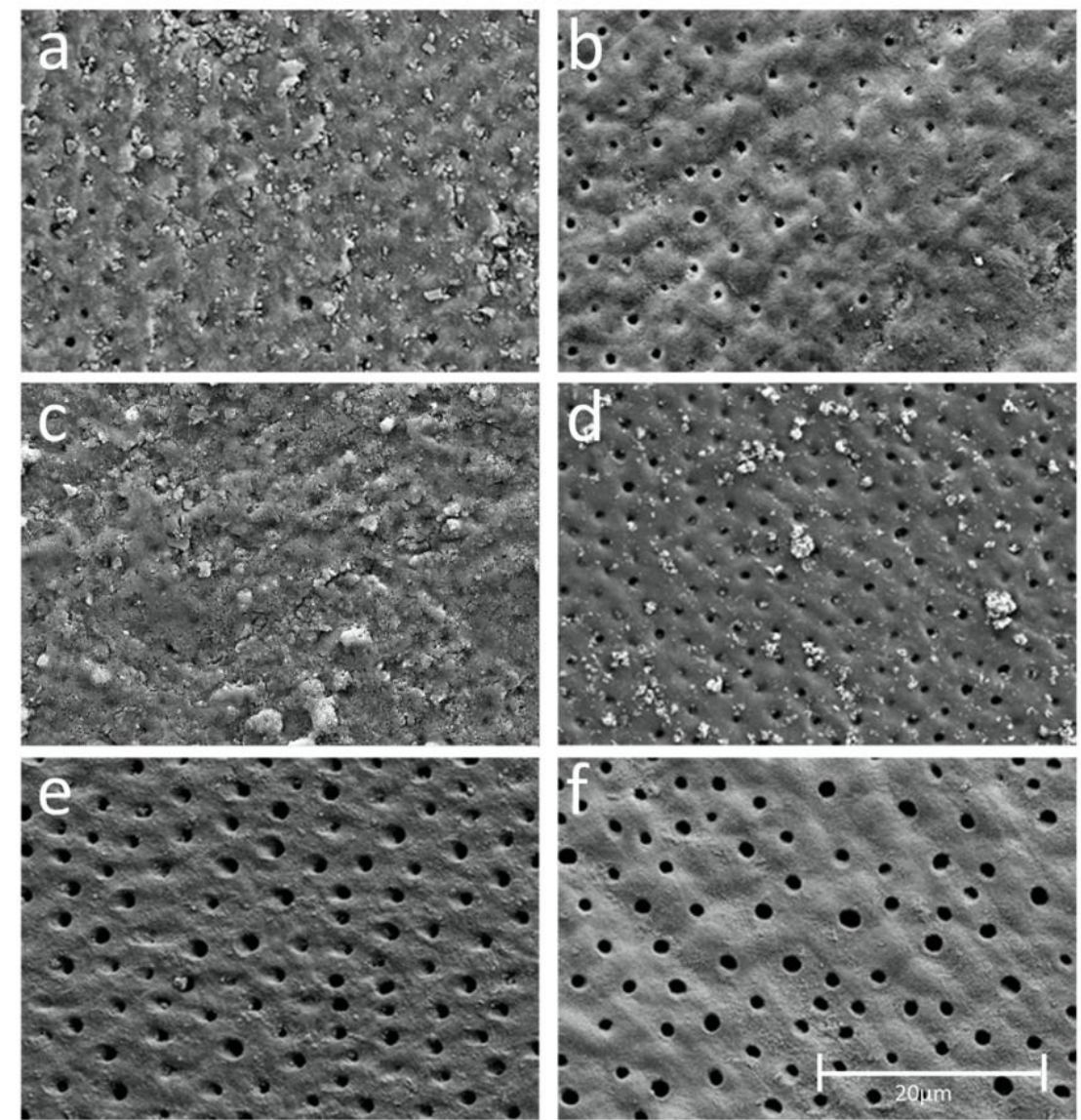

Fig 5. The view of samples after the application of test agents. While the dentin tubules were completely occluded by test agents in Fig $5 a$ and $5 c$, the image in $5 b$ and $5 d$ showed nearly half-occluded dentinal tubules. The test agent in fig 5e showed no efficacy on dentinal tubules for occluding like control group. a: TM, b: SP, c: Novamin, d: ACC, e: PO, f: Control

For the home-based products, the percentage of occlusion in dentin tubules was highest in group $\mathrm{N}$ while group ACC and group PO showed a lower level of occlusion. Before the citric acid treatment, there were statistically significant differences among these three products $(p=0.000, p=0.000, p=0.013)$. After citric acid application, group $\mathrm{N}$ showed a dramatic decrease in median value, and its dentinal occlusion could not resist against acid attack. However, while group ACC and PO lost some resistance to the acid attack this decrease was not much in the group N. In-group comparison of resistance against acid attack demonstrated that the alterations in these three products were statistically significant $(p=0.45)$.

Before the citric acid challenge, when in-office and home-based products were evaluated together, the highest percentage of dentinal occlusion was found to be group $\mathrm{N}, \mathrm{TM}, \mathrm{ACC}, \mathrm{SP}$ and $\mathrm{PO}$, respectively. According to these results, the difference between group $\mathrm{N}$ and TM were statistically insignificant, but they showed significant results compared to other test agents $(p<0.05)$. In the same way, group ACC and SP did not show statistically significant results. However; while group ACC showed a statistically powerful difference compared to group N, TN, and PO $(p<0.05)$; group SP showed a statistically significant difference compared to group $N$ and TM ( $p=0.000)$, but it showed no difference compared to group PO. Group PO showed no statistical difference only when compared to group SP (Fig. 5) (Table 5).

After the citric acid challenge, there were also no statistically significant differences between some test agents. For instance, there was no statistically significant difference among group TM, SP and ACC. On the other hand, group TM showed a statistically powerful difference compared to group $\mathrm{N}$ and $\mathrm{PO}$ $(p=0.011, p=0.000)$. The quantitative differences between group SP, ACC and N were not statistically significant, and group SP and ACC showed a significant difference compared to group $P O(p=0.000, p=0.045)$ (Fig. 6). Finally, differences in group $\mathrm{N}$ and $\mathrm{PO}$ were statistically insignificant (Fig. 7 and 8).

As to resistance of the test agents against citric acid, group SP continued its effect on occluded tubules and showed resistance against acid. Group PO and ACC have shown resistance although not as much as group SP. However, there was a statistically significant difference among these three groups $(p<0.001)$. The differences in group $\mathrm{N}$ and SP with group $\mathrm{N}$ and TM were statistically significant $(p<0.001)$. On the other hand, the differences between group ACC and TM were not statistically significant. In addition, group TM and $\mathrm{N}$ were statistically insignificant $(p<0.001)($ Table 4,5$)$. 

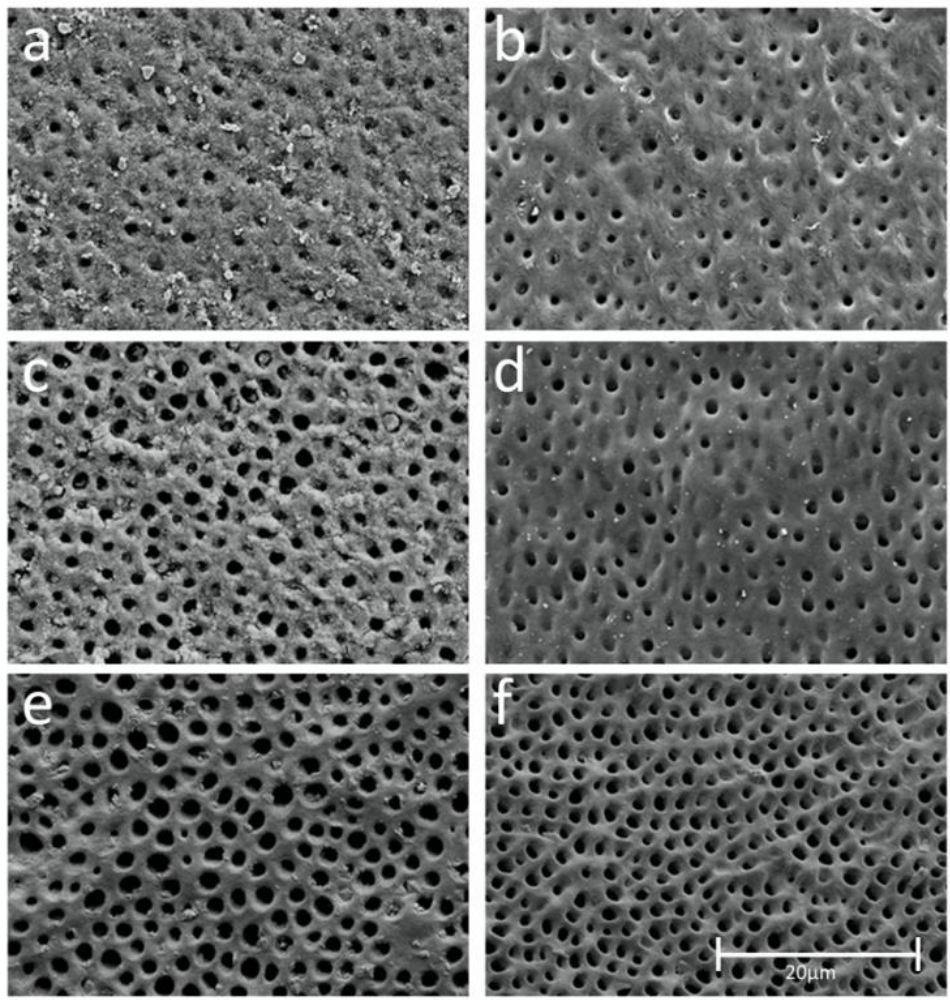

Figure 6. The view of samples after exposure of citric acid. The test agent in fig $5 \mathrm{~b}$ sustained efficacy on dentinal tubules but especially fig $5 c$ showed failure to preserve the occluding of the dentinal tubules. a: TM, b: SP, c: Novamin, d: ACC, e: PO, f: Control

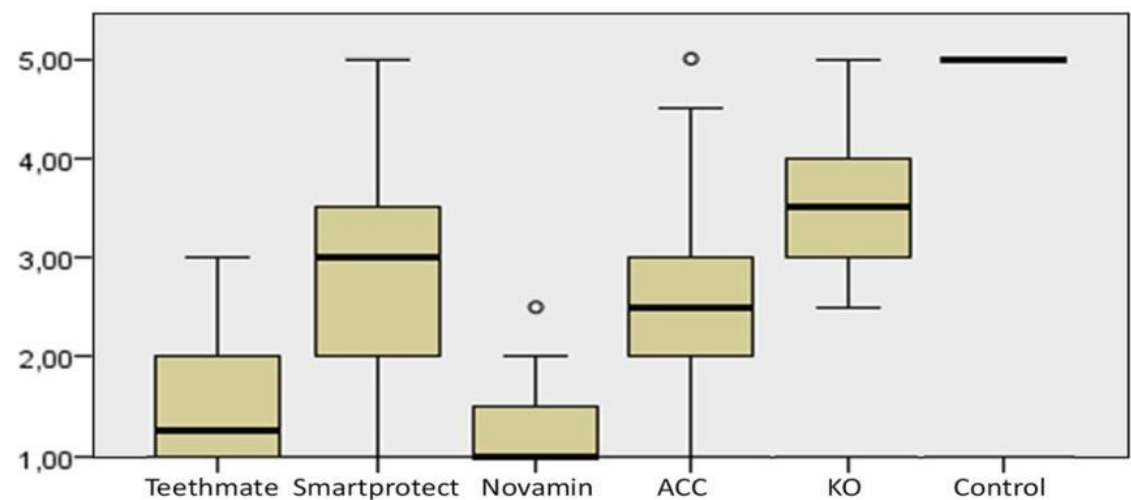

Figure 7. The graphical projection of scoring on samples in respect of groups before application of test agents

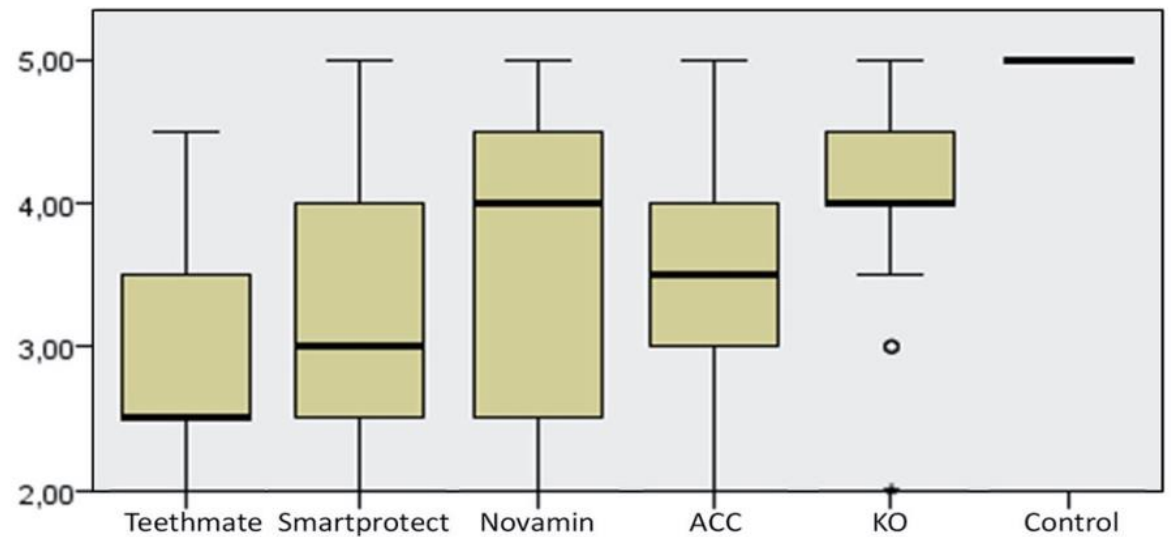

Figure 8. The graphical projection of scoring on samples in respect of groups after application of test agents. 
Table 4. Comparison of alterations occured in tubules after acid exposure with respect to tubule occlusion after application of agents.

\begin{tabular}{lc}
\hline Study groups & The level of change \\
\hline Teethmate & $1(-1-3)^{\mathrm{ac}}$ \\
\hline Smartprotect & $0(-3-4)^{\mathrm{b}}$ \\
\hline Novamin & $2,3(0-4)^{\mathrm{a}}$ \\
\hline Arginine calcium carbonate & $0,5(-2-4)^{\mathrm{bc}}$ \\
\hline Potassium oxalate & $0,5(-2-3)^{\mathrm{b}}$ \\
\hline Control (saline) & $0(0-0)^{\mathrm{b}}$ \\
\hline Same superscripts show indifference among groups, statistical significance level; $<0,05$
\end{tabular}

Table 5. $\mathrm{p}$ values of desensitizers comparisons

\begin{tabular}{|c|c|c|c|c|c|c|}
\hline \multicolumn{7}{|c|}{ Before acid/ After acid (p values) } \\
\hline Groups & Teethmate & Smartprotect & Novamin & ACC & $\begin{array}{l}\text { Potassium } \\
\text { oxalate }\end{array}$ & Control \\
\hline Teethmate & - & $.000 * / 1.000$ & $1.000 / .011^{*}$ & $.006 * / .091$ & $.000 * / .000 *$ & $.000 * / .000 *$ \\
\hline Smartprotect & $.000 * / 1.000$ & - & $.000 * / .545$ & $1.000 / 1.000$ & $.799 / .000 *$ & $.000 * / .000 *$ \\
\hline Novamin & $1.000 / .011^{*}$ & $.000 * / .545$ & - & $.000 * / 1.000$ & $.000 * / .304$ & $.000 * / .000 *$ \\
\hline $\mathrm{ACC}$ & $.006 * / .091$ & $1.000 / 1.000$ & $.000 * / .545$ & - & $.013 * / .045^{*}$ & $.000 * / .000 *$ \\
\hline $\begin{array}{c}\text { Potassium } \\
\text { oxalate }\end{array}$ & $.000 * / .000 *$ & $.799 / .000 *$ & $.000 * / .304$ & $.013 * / .045^{*}$ & - & $.000 * / .000 *$ \\
\hline Control & $.000 * / .000 *$ & $.000 * / .000 *$ & $.000 * / .000 *$ & $.000 * / .000 *$ & $.000 * / .000 *$ & - \\
\hline
\end{tabular}

\section{Discussion}

$\mathrm{DH}$ is an important problem in dentistry and has a prevalence of $4-74 \%$ (19). Toothpaste, mouth rinses, and several dental products act by releasing antimicrobial and anti-sensitive agents on dentin tubules. Saliva, which acts as a lavation and protective in the mouth, performs the blockage of the dentin tubules with calcium and phosphate ions. However, in the $\mathrm{DH}$ occurring causing by reasons such as tooth abrasion and tooth erosion, the calcium and phosphate ions in saliva are inadequate because of slow-release, and so there is a need for an external intake to prevent the dentinal sensitivity (18). In this study, the efficacy of five different desensitizer materials was evaluated.

According to the present study, superiority in group $\mathrm{N}$ and TM materials were similar to other studies before the citric acid challenge. In some in vitro studies; researchers have suggested that novamin ${ }^{\circledR}$ toothpaste was more efficient on dentinal tubules (2024) than Pro-Argin ${ }^{\mathrm{TM}}$, which have also been demonstrated in clinical studies $(25,26)$. However, there are some studies stating that novamin $\circledast$ was not superior to ACC and even failed to close the dentin tubules $(18,27,28)$. The superiority of TM compared to ACC which has been suggested in this study is supported by other studies $(29,30)$.

Novamin $®$ containing dentifrice shows the effect with the sodium and calcium phosphosilicate compound on dentin tubules. This mechanism creates an affinitive effect for collagen and thus occludes the dentinal tubules $(31,32)$. Upon TM application on dentin tubules, calcium and phosphate ions reach saturation and spontaneously form hydroxyapatite $(33,34)$. Some studies showed that crystallized products penetrated into the dentin tubules $(30,35)$. After citric acid challenge, TM test agent protected the gains in the occlusion of dentin tubules. According to current studies, it could be claimed that TM influenced the dentin tubules with the process of crystallization. This process is explained as follow: the mixed compound of tetra calcium phosphate and dicalcium phosphate anhydrous in the TM material is applied to the surface of dry dentin, and then the resulting compound is converted into hydroxyapatite in aqueous environment $(36,37)$.

Smartprotect group was the second test agent providing the blockage of the dentin tubules after the acid attack following TM but there was no statistical difference between these agents. SP has not lost its effectiveness even after acid challenge. SP contained the fluoride occludes the dentin tubules through a certain mechanism, by which triggering the accumulation of $\mathrm{CaF} 2$, thus on dentin layer decreases the permeability of dentinal tubules (38). In addition, the fluoride has been shown to form a strong barrier against citric acid (39). TM agent has been shown to be resistant against acid applications in other studies, and the results were similar to this study $(30,33)$. In this study, not only the toothpaste with Novamin ${ }^{\circledR}$ containing dentifrice has dramatically lost its effectiveness on the dentinal tubules after citric acid challenge, but also ACC toothpaste lost its efficiency. Although ACC agent showed superiority compared to novamin $₫$, there was no statistical difference between these agents. On the other hands, there was statistically significant differences in the dentinal occlusion results of Novamin $®, A C C$ and PO agents when compared to that of the control group (saline). These results were accordance to other studies. For 
instance, an in vitro study performed by Chen et al. (18), demonstrated that the efficacy in dentine tubules against acid attack between Novamin $₫$ and ACC were not statistically significant but superior to saline. Lavenden et al. (40) and Li et al. (41) claimed that the occlusion of ACC was more resistant to acid challenge than that of Novamin ${ }^{\circledR}$. In another in situ study, West et al (23) evaluated the efficiency of ACC and Novamin $\AA$ samples in the oral environment after obtaining dentin discs. The dentinal occlusion constituted by ACC was more persistent than that of Novamin $\AA$. However, as in the current study, the difference was not significant. In another in vitro study, Bakri et al. (22) stated that Novamin $®$ and ACC were statistically superior to saline. Unlike the results of this study, they reported that Novamin $®$ was more resistant to acid attack than ACC. Parkinson et al. (42) also asserted that Novamin $₫$ toothpaste was superior to ACC toothpaste. The different results obtained in this study may be caused by the different duration of acid challenge applied in this study, and also by the methodological differences. The results obtained from some clinical studies presented the similarly with results of this in vitro study, in which not observing any difference between novamin $₫$ and ACC agents $(28,43)$.

The first in vitro study published in 2013 regarding $\mathrm{PO}$ agent showed favourable results when compared to desensitizing toothpaste and POcontaining mouth rinse was found considerably successful in terms of resistance against acid (44). However, in the clinical study performed by the same researcher, it was stated that PO was exceeded by Sensodyne original in terms of patients' comfort (45). In this in vitro study, PO was relatively less successful compared to other desensitizing test agents for the occlusion of dentin tubules.

The limitation of this experimental study is that the results obtained in dentin discs may be controversial due to the elimination of the factors in clinical conditions. The findings in clinical trials to monitor $\mathrm{DH}$ indicate that after improvements in oral hygiene, calcium, phosphate and proteins in saliva can lead to more accumulation with increased contact between saliva and dentin surface, thereby increasing the occlusion of dentin tubules (46). According to the mechanism of ACC; toothpastes containing a combination of calcium carbonate and arginine reduce the occurring $\mathrm{DH}$ in the presence of calcium, phosphate and salivary glycoproteins (47). Arginine, a naturally occurring amino acid in saliva, acts simultaneously with calcium carbonate and phosphate to form a plug-in in the dentinal tubules, thereby preventing fluid flow (48). Since this study is not a clinical trial, the potential effect of ACC may not have been observed. The reason for the differences in the results obtained in this experimental study from the clinical results in other studies is related to these factors.

\section{Conclusions}

It was evaluated the different desensitizing agents as home-care and professional-care in this study. Thus, TM presented the most successful results after agent application. However, SP was the most resistant test agent against acid attacks. Although the Novamin ${ }^{\circledR}$ had the successful occlusion agent in dentine tubules, it lost almost whole efficiency after acid attacks.

Ethical Approval: Ethics committee approval was received for this study from Karabük University, Ethics Committee in accordance the World Medical Association Declaration of Helsinki, with the approval number: 2018/4-23.

Peer-review: Externally peer-reviewed.

Author Contributions: Conception - F.K.; Design - FK., O.F.A.; Supervision - F.K.; Materials - F.K., O.F.A,; Data Collection and/or Processing - F.K., O.F.A,; Analysis and/or Interpretation - O.F.A.; Literature Review - FK., O.F.A,; Writer - FK., O.F.A,; Critical Review - O.F.A.

Conflict of Interest: No conflict of interest was declared by the authors.

Financial Disclosure: The authors declared that this study has received no financial support.

Acknowledgment: We would like to thank Karabük University for their contributions. We are thankful Research Assistant Yasin Akgül, Emrah Aydın and Salih Bektas for valuable contributions. This study was supported by Karabük University Scientific Research Projects Office (KBÜBAP-18-DS-091). We thank Karabük University for their contributions.

\section{References}

1. Löst C. Depth of alveolar bone dehiscences in relation to gingival recessions. J Clin Periodontol 1984;11(9):583-9. (Crossref)

2. Beck JD, Koch GG. Characteristics of older adults experiencing periodontal attachment loss as gingival recession or probing depth. J Periodontal Res 1994;29(4):290-8. (Crossref)

3. Lafzi A, Abolfazli N, Eskandari A. Assessment of the etiologic factors of gingival recession in a group of patients in Northwest Iran. J Dent Res Dent Clin Dent Prospects 2009;3(3):90-3.

4. Ruf S, Hansen K, Pancherz H. Does orthodontic proclination of lower incisors in children and adolescents cause gingival recession? Am J Orthod Dentofacial Orthop 1998;114(1):100-6. (Crossref)

5. West NX, Lussi A, Seong J, Hellwig E. Dentin hypersensitivity: pain mechanisms and aetiology of exposed cervical dentin. Clin Oral Investig 2013;17(1):9-19. (Crossref)

6. Holland GR, Narhi MN, Addy M, Gangarosa L, Orchardson R. Guidelines for the design and conduct of clinical trials on dentine hypersensitivity. J Clin Periodontol 1997;24(11):80813. (Crossref)

7. Amaechi BT, Lemke KC, Saha S, Gelfond J. Clinical Efficacy in Relieving Dentin Hypersensitivity of Nanohydroxyapatitecontaining Cream: A Randomized Controlled Trial. Open Dent J 2018;12:572-85. (Crossref)

8. Cartwright RB. Dentinal hypersensitivity: a narrative review. Community Dent Health 2014;31:15-20.

9. Bartold PM. Dentinal hypersensitivity: a review. Aust Dent J 2006;51:212-8. (Crossref)

10. 10. Walters PA. Dentinal hypersensitivity: a review. J Contemp Dent Pr 2005;6:107-17. (Crossref)

11. Pashley DH. How can sensitive dentine become hypersensitive and can it be reversed? J Dent 2013;41:49-55. (Crossref)

12. Schmidlin PR, Sahrmann P. Current management of dentin hypersensitivity. Clin Oral Investig 2013;17:55-9. (Crossref)

13. Acar O, Tuncer D, Yuzugullu B, Celik C. The effect of dentin desensitizers and Nd: YAG laser pre-treatment on microtensile 
bond strength of self-adhesive resin cement to dentin. J Adv Prosthodont 2014;6:88-95. (Crossref)

14. Pradeep AR, Sharma A. Comparison of clinical efficacy of a dentifrice containing calcium sodium phosphosilicate to a dentifrice containing potassium nitrate and to a placebo on dentinal hypersensitivity: a randomized clinical trial. J Periodontol 2010;81:1167-73. (Crossref)

15. Cummins D. Recent advances in dentin hypersensitivity: clinically proven treatments for instant and lasting sensitivity relief. Am J Dent 2010;23:3-13. (Crossref)

16. Sauro S, Gandolfi MG, Prati C, Mongiorgi R. Oxalate-containing phytocomplexes as dentine desensitisers: An in vitro study. Arch Oral Biol 2006;51:655-64. (Crossref)

17. Arrais CAG, Chan DCN, Giannini M. Effects of desensitizing agents on dentinal tubule occlusion. J Appl Oral Sci 2004;12:144-8. (Crossref)

18. Chen CL, Parolia A, Pau A, Celerino de Moraes Porto IC. Comparative evaluation of the effectiveness of desensitizing agents in dentine tubule occlusion using scanning electron microscopy. Aust Dent J 2015;60:65-72. (Crossref)

19. Jung JH, Park SB, Yoo KH, et al. Effect of different sizes of bioactive glass-coated mesoporous silica nanoparticles on dentinal tubule occlusion and mineralization. Clin Oral Investig 2019;23(5):2129-41. (Crossref)

20. Reddy GV, Akula S, Malgikar S, Babu PR, Reddy GJ, Josephin JJ. Comparative scanning electron microscope analysis of diode laser and desensitizing toothpastes for evaluation of efficacy of dentinal tubular occlusion. J Indian Soc Periodontol 2017;21:102-6. (Crossref)

21. Cunha SR, Garófalo SA, Scaramucci T, Zezell DM, Aranha ACC. The association between Nd:YAG laser and desensitizing dentifrices for the treatment of dentin hypersensitivity. Lasers Med Sci 2017;32:873-80. (Crossref)

22. Bakri MM, Hossain MZ, Razak FA, et al. Dentinal tubules occluded by bioactive glass-containing toothpaste exhibit high resistance toward acidic soft drink challenge. Aust Dent J 2017;62:186-91. (Crossref)

23. West NX, Macdonald EL, Jones SB, Claydon NCA, Hughes N, Jeffery $P$. Randomized in situ clinical study comparing the ability of two new desensitizing toothpaste technologies to occlude patent dentin tubules. J Clin Dent 2011;22:82-90.

24. Kulal R, Jayanti I, Sambashivaiah S, Bilchodmath S. An In-vitro Comparison of Nano Hydroxyapatite, Novamin and Proargin Desensitizing Toothpastes - A SEM Study. J Clin Diagn Res JCDR 2016;10:51-4. (Crossref)

25. Majji $P$, Murthy KRV. Clinical efficacy of four interventions in the reduction of dentinal hypersensitivity: A 2-month study. Indian J Dent Res Off Publ Indian Soc Dent Res 2016;27:477-82. (Crossref)

26. Chatas R, Wójcik-Chęcińska I, Zamościńska J, Bachanek T. Assessment of Pain Intensity in Patients with Dentin Hypersensitivity After Application of Prophylaxis Paste Based on Calcium Sodium Phosphosilicate Formula. Med Sci Monit Int Med J Exp Clin Res 2015;21:2950-5. (Crossref)

27. Jena A, Shashirekha G. Comparison of efficacy of three different desensitizing agents for in-office relief of dentin hypersensitivity: A 4 weeks clinical study. J Conserv Dent JCD 2015;18:389-93. (Crossref)

28. Fu $Y$, Sufi $F$, Wang $N$, Young $S$, Feng $X$. An Exploratory Randomised Study to Evaluate the Efficacy of an Experimental Occlusion-based Dentifrice in the Relief of Dentin Hypersensitivity. Oral Health Prev Dent 2019;17:107-15.

29. Zhou J, Chiba A, Scheffel DLS, et al. Effects of a Dicalcium and Tetracalcium Phosphate-Based Desensitizer on In Vitro Dentin Permeability. PloS One. 2016; PLOS ONE 11(6): e0158400 (Crossref)

30. Medvecky L, Stulajterova R, Giretova M, et al. Effect of tetracalcium phosphate/monetite toothpaste on dentin remineralization and tubule occlusion in vitro. Dent Mater Off Publ Acad Dent Mater 2018;34:442-51. (Crossref)

31. Earl JS, Leary RK, Muller KH, Langford RM, Greenspan DC. Physical and chemical characterization of dentin surface following treatment with NovaMin technology. J Clin Dent 2011;22:62-7.

32. Layer TM. Development of a fluoridated, daily-use toothpaste containing NovaMin technology for the treatment of dentin hypersensitivity. J Clin Dent 2011;22:59-61.

33. Kyaw KY, Otsuki M, Segarra MS, Hiraishi N, Tagami J. Effect of Calcium-phosphate Desensitizers on Staining Susceptibility of Acid-eroded Enamel. Oper Dent 2019;44(3):281-8. (Crossref)

34. Nakata T, Kitasako Y, Sadr A, Nakashima S, Tagami J. Effect of a calcium phosphate and fluoride paste on prevention of enamel demineralization. Dent Mater J 2018;37:65-70. (Crossref)

35. Ishihata $\mathrm{H}$, Kanehira M, Finger WJ, Takahashi H, Tomita M, Sasaki K. Effect of two desensitizing agents on dentin permeability in vitro. J Appl Oral Sci Rev FOB 2017;25:34-41. (Crossref)

36. Thanatvarakorn O, Nakashima S, Sadr A, Prasansuttiporn T, Thitthaweerat S, Tagami J. Effect of a calcium-phosphate based desensitizer on dentin surface characteristics. Dent Mater J 2013;32:615-21. (Crossref)

37. Thanatvarakorn $O$, Nakashima S, Sadr A, Prasansuttiporn T, Ikeda M, Tagami J. In vitro evaluation of dentinal hydraulic conductance and tubule sealing by a novel calcium-phosphate desensitizer. J Biomed Mater Res B Appl Biomater 2013;101:303-9. (Crossref)

38. Miglani S, Aggarwal V, Ahuja B. Dentin hypersensitivity: Recent trends in management. J Conserv Dent JCD 2010;13:218-24. (Crossref)

39. Favretto CO, Delbem ACB, Moraes JCS, Camargo ER, de Toledo PTA, Pedrini D. Dentinal tubule obliteration using toothpastes containing sodium trimetaphosphate microparticles or nanoparticles. Clin Oral Investig 2018;22:3021-9. (Crossref)

40. Lavender SA, Petrou I, Heu R, et al. Mode of action studies on a new desensitizing dentifrice containing $8.0 \%$ arginine, a high cleaning calcium carbonate system and $1450 \mathrm{ppm}$ fluoride. Am J Dent 2010;23:14-9.

41. Li R, Li Y, Chen J, Zhou Z, Morrison BM, Panagakos FS. Efficacy of a desensitizing toothpaste containing arginine and calcium carbonate on dentin surface pore structure and dentin morphology. Am J Dent 2012;25:210-4.

42. Parkinson CR, Willson RJ. A comparative in vitro study investigating the occlusion and mineralization properties of commercial toothpastes in a four-day dentin disc model. J Clin Dent 2011;22:74-81.

43. Lopes RM, Scaramucci T, Aranha ACC. Effect of desensitizing toothpastes on dentin erosive wear and tubule occlusion. An in situ study. Am J Dent 2018;31:177-83.

44. Sharma D, Hong CX, Heipp PS. A novel potassium oxalatecontaining tooth-desensitising mouthrinse: a comparative in vitro study. J Dent 2013;41(4):18-27. (Crossref)

45. Sharma D, McGuire JA, Gallob JT, Amini P. Randomised clinical efficacy trial of potassium oxalate mouthrinse in relieving dentinal sensitivity. J Dent 2013;41(4):40-8. (Crossref)

46. West NX, Addy M, Jackson RJ, Ridge DB. Dentine hypersensitivity and the placebo response. A comparison of the effect of strontium acetate, potassium nitrate and fluoride toothpastes. J Clin Periodontol 1997;24:209-15. (Crossref)

47. Mockdeci H, Polonini H, Martins I, Granato AP, Raposo N, Chaves MG. Evaluation of ex vivo effectiveness of commercial desensitizing dentifrices. J Clin Exp Dent 2017;9(4):503-10. (Crossref)

48. Cummins D. Advances in the clinical management of dentin hypersensitivity: a review of recent evidence for the efficacy of dentifrices in providing instant and lasting relief. J Clin Dent 2011;22:97-9. 